\title{
Working hours and productivity
}

Citation for published version (APA):

Collewet, M., \& Sauermann, J. (2017). Working hours and productivity. ROA. ROA Research Memoranda No. 004 https://doi.org/10.26481/umaror.2017004

Document status and date:

Published: 01/01/2017

DOI:

10.26481/umaror.2017004

Document Version:

Publisher's PDF, also known as Version of record

\section{Please check the document version of this publication:}

- A submitted manuscript is the version of the article upon submission and before peer-review. There can be important differences between the submitted version and the official published version of record.

People interested in the research are advised to contact the author for the final version of the publication, or visit the DOI to the publisher's website.

- The final author version and the galley proof are versions of the publication after peer review.

- The final published version features the final layout of the paper including the volume, issue and page numbers.

Link to publication

\footnotetext{
General rights rights.

- You may freely distribute the URL identifying the publication in the public portal. please follow below link for the End User Agreement:

www.umlib.nl/taverne-license

Take down policy

If you believe that this document breaches copyright please contact us at:

repository@maastrichtuniversity.nl

providing details and we will investigate your claim.
}

Copyright and moral rights for the publications made accessible in the public portal are retained by the authors and/or other copyright owners and it is a condition of accessing publications that users recognise and abide by the legal requirements associated with these

- Users may download and print one copy of any publication from the public portal for the purpose of private study or research.

- You may not further distribute the material or use it for any profit-making activity or commercial gain

If the publication is distributed under the terms of Article $25 \mathrm{fa}$ of the Dutch Copyright Act, indicated by the "Taverne" license above, 


\section{Working hours and productivity}

Marion Collewet

Jan Sauermann

\section{ROA Research Memorandum}

ROA-RM-2017/4

Researchcentrum voor Onderwijs en Arbeidsmarkt | ROA Research Centre for Education and the Labour Market | ROA 


\title{
Working hours and productivity
}

\author{
Marion Collewet \\ Jan Sauermann
}

ROA-RM-2017/4*

April 2017

Research Centre for Education and the Labour Market

Maastricht University

P.O. Box 616, 6200 MD Maastricht, The Netherlands

$\mathrm{T}+31433883647 \mathrm{~F}+31433884914$

secretary-roa-sbe@maastrichtuniversity.nl

www.roa.nl

\footnotetext{
* The ROA Research Memorandum Series was created in order to make research results available for discussion, before those results are submitted for publication in journals.
} 


\section{Abstract}

\section{Working hours and productivity**}

This paper studies the link between working hours and productivity using daily information on working hours and performance of a sample of call centre agents. We exploit variation in the number of hours worked by the same employee across days and weeks due to central scheduling, enabling us to estimate the effect of working hours on productivity. We find that as the number of hours worked increases, the average handling time for a call increases, meaning that agents become less productive. This result suggests that fatigue can play an important role, even in jobs with mostly parttime workers.

JEL classification: J23, J22, M12, M54

Keywords: working hours, productivity, output, labour demand

Marion Collewet

Centre for Operations Research and

Econometrics (CORE)

Université Catholique de Louvain

Voie du Roman Pays, 34 - L1.03.01

B-1348 Louvain-la-Neuve

Belgium

marion.collewet@uclouvain.be

and ROA, Maastricht University
Jan Sauermann

Swedish Institute for Social Research

Stockholm University

Universitetsvägen $10 \mathrm{~F}$ (floors 8 and 9)

SE-106 91 Stockholm

Sweden

jan.sauermann@sofi.su.se

and ROA, Maastricht University and IZA

** The authors would like to thank Jordi Blanes-I-Vidal, Alexandra de Gendre, Andries De Grip, Annemarie KünnNelen, John Pencavel, two anonymous referees, and seminar participants at the Paris School of Economics, and audience at EALE 2016 for valuable comments and suggestions. Jan Sauermann gratefully acknowledges financial support from the Jan Wallanders och Tom Hedelius Stiftelse for financial support (Grant number I2011-0345:1). 


\section{Introduction}

Hours worked vary substantially between countries, but also within countries, e.g. due to the prevalence of part-time work and working hours regulations or agreements (Bick et al., 2016; OECD, 2016). Understanding how the number of hours worked affects labour productivity is an important element of understanding labour demand, and has important implications for the regulation of working hours and firm management. Still, a lot remains unknown about the effect of working hours on labour productivity. In theory, there could be two opposite effects. On the one hand, longer hours can lead to higher productivity if a worker faces fixed set-up costs and fixed unproductive time during the day, or if longer hours lead to better utilisation of capital goods (Feldstein, 1967). On the other hand, worker fatigue could set in after a number of hours worked, so that the marginal effect on productivity of an extra hour per worker starts decreasing (Pencavel, 2015). If neither of these effects apply, or if both cancel each other out, it could also be the case that marginal productivity does not change with working time, so that output is proportional to the number of hours worked. Identifying the effect of working time on productivity is not straightforward for two main reasons. First, unobservable characteristics of industries, firms, jobs and individuals are likely to influence both working time and productivity, so that the correlation between the two variables is likely to be a biased estimate of the effect of working time on productivity. Second, external shocks could influence both working time and productivity, which again leads to a biased estimation of the effect.

In this paper, we study the influence of the daily number of hours worked on workers' productivity using panel data from a call centre in the Netherlands from mid-2008 to the first week of 2010 (cf. De Grip and Sauermann, 2012; De Grip et al., 2016). For each of the 332 workers in our sample, the data contain detailed information on the number of daily working hours, and workers' individual performance, as measured by the average handling time of calls. The panel structure of our data set allows us to correct for timeinvariant unobserved characteristics of individuals that may influence both 
working time and productivity. Moreover, the exact number of hours worked by a worker on a given day is determined by central planning. Expected customer demand determines the scheduling process, and schedules are hardly related to individual preferences. This enables us to obtain estimates of the effect of working time on productivity.

Estimating a model controlling for individual fixed effects and several types of time fixed effects, we find that an increase in working hours by 1 percent leads to an increase in output by only 0.9 percent, measured as the number of calls answered. This finding suggests that fatigue sets in as working time increases. The corresponding decrease in productivity is mild in this sample where most employees work part-time, but it suggests that fatigue effects would be much stronger if agents would work full-time. We find evidence of more strongly decreasing returns to hours for workers with shorter tenure, a result that is not driven by worker attrition. Using additional data on service quality, we find that longer working hours are associated with a moderate increase of call quality in working hours, a result that partly offsets the negative effect on the number of calls answered.

This paper contributes to a rich literature that studies the link between working time and productivity. Studies estimating production functions based on industry-level data find mixed evidence for the returns to working hours. Whereas some studies find increasing returns to hours (Feldstein, 1967; Craine, 1973; Leslie, 1984), which could be the result of not taking capacity utilisation rates into account (e.g. Tatom, 1980), or be due to aggregation bias (e.g. DeBeaumont and Singell, 1999), other studies conclude that output is roughly proportional to hours worked per worker (Hart and McGregor, 1988; Anxo and Bigsten, 1989; Ilmakunnas, 1994). The majority of studies, however, find evidence of decreasing returns to hours (e.g. Leslie and Wise, 1980; Tatom, 1980; DeBeaumont and Singell, 1999; Shepard and Clifton, 2000). Typically, studies using aggregate data deal with the endogeneity of working time by using panel data and including industry fixed effects, and by instrumenting for working time using lagged values or ranks. The validity of such instruments, however, can be questioned, and the mea- 
surement of working time and output at these aggregate levels is likely to be subject to error.

Studies using firm-level data, or data from workers in individual firms or in specific sectors are typically better at dealing with the endogeneity of working hours. A few studies use panels of firms to estimate the link between working time and firm or establishment productivity (Crépon et al., 2004; Schank, 2005; Kramarz et al., 2008; Gianella and Lagarde, 2011). They tend to find that output is roughly proportional to the number of hours worked. ${ }^{1}$ Due to the data structure, these studies are able to control for the endogeneity of working time caused by time-invariant firm characteristics. However, shocks that would affect both working time and productivity could still form a potential source of bias.

Studies using data about individual workers in a firm, or about workers in comparable firms date back to the early 20th century, when studies descriptively analysed the relationship between working hours and output, or compared output before and after a change in working hours (Goldmark, 1912; Vernon, 1921; Kossoris, 1947). ${ }^{2}$ More recent studies, however, exploit exogenous sources of variation in working hours to address the relationship between hours and worker level productivity. An early example is the study of citrus harvesters by Crocker and Horst (1981), who use the size of the grove worked on as a source of variation in working time. Brachet et al. (2012) conduct a difference-in-differences analysis to compare performance of paramedics working on short and long shifts. Using data from munition plants in Britain during the First World War, Pencavel (2015) uses variation in working time coming from the demand for shells to estimate the effect of working time on productivity. Dolton et al. (2016) use data from the Hawthorne experiments (conducted between 1924 and 1932) to exploit

\footnotetext{
${ }^{1}$ Crépon et al. (2004) and Kramarz et al. (2008) find positive effects on productivity of participating in a working time reduction scheme for French firms, but this effect is due to the reorganisation of work that took place as a consequence of the working time reduction. Work allocation as a mechanism to explain the link between part-time work and productivity has been studied by Künn-Nelen et al. (2013), Specchia and Vandenberghe (2013), Garnero et al. (2014), and Devicienti et al. (2015).

${ }^{2}$ See Nyland (1989) for an overview of these and other studies.
} 
the fact that workers were subjected to different working times in different periods. While Crocker and Horst (1981) find that output is proportional to hours worked, Brachet et al. (2012), Pencavel (2015), and Dolton et al. (2016) find evidence of decreasing returns to hours. A contrasting result is found by $\mathrm{Lu}$ and $\mathrm{Lu}$ (2016), who exploit changes in mandatory overtime laws for nurses. They find that the introduction of overtime laws actually reduced the quality provided by nurses, an effect that can be explained by changes in staffing policies of permanent and contractual (temporary) nurses. ${ }^{3}$ We contribute to this literature by exploiting exogenous variation in working hours, which is due to the call centre's central scheduling.

Most of the studies that are able to exploit exogenous variation in working time to identify the effect of working hours on productivity have concentrated on either manual workers from the first half of the 20th century (Pencavel, 2015; Dolton et al., 2016) ${ }^{4}$, or on the health sector using more recent data (Brachet et al., 2012; Lu and Lu, 2016). In this paper, we provide evidence about call agents in a call centre. Our results can have informative value for a broader range of medium-skilled level jobs in the service sector, and are relevant for policies such as working time regulation.

The remainder of the paper is structured as follows. In the next section, we outline our conceptual framework. Section 3 presents the empirical model we estimate and our identification strategy. Section 4 describes the data we use. Section 5 presents our main estimation results. In Section 6, we conduct a number of robustness checks, and we formulate conclusions in Section 7.

\footnotetext{
${ }^{3}$ In addition to these studies, there are more studies for the health sector, typically finding decreasing returns to working hours. These studies, however, are either based on indirect performance measures (psychometric tests, simulations of work tasks, self-report questionnaires; for a review, see Kodz et al., 2003), or on correlations and before-after comparisons (Rogers et al., 2004; Hart and Krall, 2007; McClay, 2008). There is also a related literature that has analysed the link between long working hours and health (e.g. van der Hulst, 2003) and between long hours and occupational injuries (e.g. Vegso et al., 2007; Lee and Lee, 2016). These studies suggest that working long hours is detrimental for health and therefore may have negative effects on productivity.

${ }^{4}$ The relation between working time and productivity might have changed as the nature of jobs evolved. Pencavel concludes his paper stating that "it would be valuable if the analysis here could be repeated on contemporary data that contain information on workers' output and their working hours" (p. 2074).
} 


\section{Conceptual framework}

\subsection{Model}

Typically, studies of the relation between working time and productivity estimate a model of the type:

$$
Y=f(H, X)+\epsilon
$$

where $Y$ is a measure of output, $H$ a measure of hours worked, $X$ is a set of variables which are also relevant for output (the capital stock being a typical candidate), and $\epsilon$ is the error term. Very often, the relationship between log output and log hours is estimated assuming a Cobb-Douglas production function. Because we focus on productivity at the level of the individual worker, for whom capital use is constant (namely one workstation), the Cobb-Douglas function can be estimated as

$$
\ln (Y)=\alpha \cdot \ln (H)+\gamma \cdot X+\epsilon
$$

In our setting, call centre management uses a specific measure to evaluate the performance of its agents: average handling time $(A H T)$, which is based on the time taken by an individual agent to answer each call during a given day or a given week. If output $Y$ is defined as the number of calls made on a given day, it can be expressed as

$$
Y=\frac{H}{A H T}
$$

Inserting Equation (3) into (2) gives:

$$
\ln (A H T)=(1-\alpha) \cdot \ln (H)-\gamma \cdot X-\epsilon
$$

Average handling time is a negative measure of productivity, since individuals who take more time to answer calls are less productive (cf. De Grip and Sauermann, 2012). To facilitate direct interpretation of our estimation results, we multiply Equation (4) by -1 , which allows us to rewrite it to 


$$
\ln \left(\frac{1}{A H T}\right)=(\alpha-1) \cdot \ln (H)+\gamma \cdot X+\epsilon
$$

and to use $1 / A H T$ as a measure of productivity: an increase in $1 / A H T$ can therefore be interpreted as an increase in productivity.

In this model, a coefficient on $\ln (H)$ equal to zero indicates that workers' productivity does not vary with working hours, which is equivalent to constant returns to hours. A positive coefficient corresponds to increasing returns to hours, and a negative one to decreasing returns. The magnitude of the coefficient on log hours is also directly interpretable: as hours increase by 1 percent, output increases by $\alpha$ percent. If we define the coefficient on $\ln (H)$ to be $\beta=\alpha-1$, output increases by $\beta+1$ percent as hours increase by 1 percent.

We estimate the model both at the day and at the week level to address potential heterogeneity in the returns to working hours at the day and week level: at the week level, workers have time to recover from one day to another, so that returns to hours might be more positive than at the day level (cf. Pencavel, 2016). Moreover, comparing returns to hours at the day and at the week level can tell us whether productivity can be increased by distributing weekly working hours differently across days.

\subsection{Mechanisms}

Before turning to estimating the model, we want to pay closer attention to the mechanisms that link working hours to labour productivity. Why exactly would we expect labour productivity to rise or fall as working hours increase?

Potential reasons for increasing returns to hours are fixed unproductive time and better capital utilisation rates. In our setting, unproductive time cannot play a role because we study effective working time (excluding breaks, see Section 4). Capital utilisation rates are not relevant either because we focus on the level of the individual worker, who always uses exactly one workstation consisting of a phone and a computer. One possible mechanism that could lead productivity to increase with working time is what Vernon (1921) calls "practice-efficiency", i.e. the fact that one gets better at a task 
as one "warms up". ${ }^{5}$ It is an open question whether what he describes for physical work may also apply to call centre agents.

The main reason why productivity would decrease as working hours increase is worker fatigue. ${ }^{6}$ The origins of the literature on fatigue and the link between working hours and labour productivity lie in the study of the manufacturing industry in the early 20th century (Goldmark, 1912; Vernon, 1921), with physically demanding jobs and very long hours. But fatigue is still relevant in today's service economy with shorter hours. Indeed, Nyland (1989) emphasizes that the fall in working hours over the course of the twentieth century has been accompanied by an intensification of work due to the rise of scientific management, so that the optimal number of working hours has most probably dropped below levels that were recommended at the beginning of the twentieth century. In fact, the majority of studies on the link between working hours and productivity still finds decreasing returns to hours. Moreover, physical demands are not the only demands of a job. Goldmark (1912) already emphasises the important role played by speed and complexity of a task. ${ }^{7}$ Bakker et al. (2003) find that job demands are related to exhaustion and repetitive strain injury in call centre agents. The agents we study were exposed to a constant flow of incoming calls and had to solve problems that were potentially different for every single call. The manage-

\footnotetext{
5 "The complex chain of central nervous system, neuro-muscular mechanisms, nerves and muscles involved takes time to work up to its maximum efficiency, and to get into thorough running order. In fact, this efficiency is unattainable except by practice, hence I have termed it practice-efficiency." (Vernon, 1921, p. 13).

${ }^{6}$ Vernon (1921) cites the definition by the British Association Committee on Fatigue from the Economic Standpoint: it sees fatigue as the "diminution of the capacity for work which follows excess of work or lack of rest, and which is recognised on the subjective side by a characteristic malaise." (p.1). More recently, in the occupational health literature, fatigue is defined by van Dijk and Swaen (2003) as "the change in the psychophysiological control mechanism that regulates task behaviour, resulting from preceding mental and/or physical efforts which have become burdensome to such an extent that the individual is no longer able to adequately meet the demands that the job requires of his or her mental functioning; or that the individual is able to meet these demands only at the cost of increasing mental effort and the surmounting of mental resistance."

${ }^{7}$ Interestingly, she takes telephone operators as an example, and reports that a medical commission deemed a 7-hours workday too long for "telephone girls". Of course, it has to be said that the work of telephone operators was much more physically demanding than the work of call centre agents today.
} 
ment of the call centre seemed well aware of the intensity and difficulty of the task agents had to perform: without having actually measured the relation between working hours and productivity, they expected a full-time contract to be sub-optimal in terms of productivity and preferred to offer part-time contracts to their employees for that reason.

\section{Empirical strategy}

Using panel data, our empirical model can be written as

$$
\ln \left(\frac{1}{A H T_{i t}}\right)=\phi+\beta \cdot \ln \left(H_{i t}\right)+\gamma \cdot X_{i t}+\delta \cdot T_{t}+\mu_{i}+\epsilon_{i t}
$$

where the subscript $i$ stands for an individual agent, and $t$ represents the time period (day or week) examined. In this section, we first discuss how we control for potential confounders, and second how we exploit scheduling as a source of exogenous variation in working hours.

\subsection{Controlling for potential confounders}

As mentioned above, there are several factors that can result in a biased estimate of the effect of hours on productivity $(\widehat{\beta})$. First, the estimate could be biased due to characteristics of individuals that influence both their working time and their productivity, such as preferences or ability. As far as these individual characteristics are time-invariant, they can be controlled for by the individual fixed effect $\mu_{i}$ in our model. Taking account of this unobserved heterogeneity takes away an important part of the potential bias in the coefficient on $\ln \left(H_{i t}\right)$.

Second, the timing of work might be important as well. If variation in types or amounts of customer calls varies over time, and this variation results in changes of agents' productivity, it is important to control for when individuals work. ${ }^{8}$ In estimations at the day level, we control for day of the

\footnotetext{
${ }^{8}$ Note that, although we have precise information on when and how long agents are working, the data only contain information on performance on the daily level, but not by the hour.
} 
week dummies (as part of $T_{t}$ ) and for hours dummies for the time during which an individual works on a given day (as part of $X_{i t}$ ); in estimations at the week level, we control for 168 dummies that represent each hour of the week. There might also be shocks on specific days or weeks, e.g. if there are technical problems that both induce agents to stay longer hours and affect their productivity because the shocks influence the time taken to help customers or the pressure experienced by agents. To control for this possibility, our model includes day fixed effects in regressions based on daily data, or week fixed effects in regressions based on weekly data.

Third, tenure is a potential confounder. Differences in tenure between individuals at the beginning of the observation period are captured by the individual fixed effect. However, as individuals become more experienced, their productivity is likely to increase, and their working time might also evolve. If this is the case, some of the effect of tenure will unduly be attributed to working time. We therefore include a general time trend in the model. Further, in Section 6, we run additional regressions including individualspecific time trends, i.e. interactions of the individual fixed effect with the time trend. This allows us to provide evidence against the hypothesis that call centre management could give different contracts or schedules to workers who learn faster.

Fourth, attrition may also be a problem. There is relatively high turnover in our sample, resulting in that individuals who stay for relatively long in the sample may be overrepresented in our data. If more productive individuals stay longer, and if they are therefore overrepresented, we will tend to overestimate returns to hours. We address this problem by estimating our model for a balanced sub-sample in Section 6. This analysis shows that the bias caused by attrition is only limited.

Finally, the team in which an individual works may also be a confounder, in the sense that a team with more positive characteristics (more cohesive, better team leader, etc.) may both induce an agent to be willing to work longer hours and make him or her more productive. This would lead to an underestimation of the fatigue effect, i.e. an overestimation of the returns to hours. To rule this out, we include team fixed effects in our model. 


\subsection{Exogeneity of working hours due to central schedul- ing}

In our data, variation in an agent's working time from day to day or from week to week arises because contractual weekly working time does not need to be exactly enforced every week. Rather, average working time over a period of three months should be equal to contractual working time. An agent's working time for a given day is defined by the planning department, on the basis of an algorithm that forecasts customer demand, i.e. the number of incoming calls. A first version of an agent's schedule for a given day is communicated five weeks in advance, but it can be revised up to the last moment. We also know that earlier performance of agents does not influence future schedules. In principle, this ensures that the exact number of hours worked by an individual on a given day is not related to shocks affecting this individual, so that $H_{i t}$ is not correlated with $\epsilon_{i t}$, the idiosyncratic error term.

There are two potential ways in which individual preferences could in theory still influence working time on a given day or a given week. First, agents are allowed to state preferences about their schedule, both general preferences and preferences for specific days or weeks, without having a guarantee that these preferences can be respected. While general preferences stated by an agent about his or her schedule are captured by the individual fixed effect, preferences concerning a specific day or week are not. Second, in case of unexpectedly high or low demand at the last minute, agents are asked to stay longer or leave earlier on a voluntary basis, with a corresponding adjustment in their pay. In theory, these two factors leave some room for the agents to work more on days on which they expect to be more productive, leading to an overestimation of the returns to hours. However, these potential sources of bias do not appear to play an important role in practice. In Section 6, we present estimations including scheduled hours (or deviations from schedules) as an additional control variable. This enables us to check whether, conditional on the actual number of hours worked, schedules (or deviations from schedules) are still related to productivity, which would hint at self-selection by agents. We show that there is only very limited evidence 
of self-selection, and that taking it into account barely changes our results. We conclude that, conditional on our set of fixed effects, scheduling can be considered an exogenous source of variation in working hours.

\section{Data}

\subsection{Description of the context}

We use rich company data on call agents employed in a call centre located in the Netherlands. This customer service centre handles calls from current and prospective customers of a mobile telecommunication company. The call centre comprises five departments, which are segmented by customer groups. To focus on workers which have comparable performance, we limit the sample to the largest department, for customers with fixed contracts.

In this department, all call agents have the same task, answering customer calls. Customers call the call centre in case of problems, complaints or questions and are routed to available agents. Typically, at a given moment, the number of incoming calls exceeds the number of available agents, generating non-zero waiting time for customers. Agents who have completed a call faster are automatically linked to the next customer waiting. This means that fast agents do not have longer breaks and do not need to wait for the next customers. Therefore, agents have little slack time when on the job. In other words, the number of hours that agents spend answering calls, our main measure of working time, is very close to the number of hours during which agents are available for calls.

Agents are incentivised to perform, and in particular to handle calls fast. Agents are organised in 19 teams, each of which is led by a team leader. The main task of team leaders is to monitor and evaluate the agents of his or her team. For this purpose, team leaders receive weekly scorecards with detailed information of their agents' performance (including average handling time), and regularly listen to the calls of their agents. Agents receive a fixed 
wage per hour. ${ }^{9}$ Following a performance appraisal of the team leader, the agent receives a grade from 1 (worst) to 5 (best), which determines both the size of an annual wage increase and an annual bonus. This grade is determined by both the performance over the year, but also by other, more subjective factors, such as the behaviour towards co-workers. The maximum wage increase depends on the firm performance, and does not exceed $8 \%$ for agents with the highest grade. ${ }^{10}$ Otherwise, there are no explicit incentives based on agents' performance, such as piece rates or bonuses upon their daily or weekly performance.

Our data comprise daily performance information for each agent working in the call centre. In total, our analysis includes 332 agents on 33,123 agent-working days, over an observation period from week 36/2008 to week 1/2010. Descriptive statistics for the estimation sample are provided in Table 1. Besides information on performance, the data also contain information on the working hours and on some basic characteristics of the agents. The majority of the agents is female, only $35 \%$ of all agents are men. Agents are on average 29 years old, and the average tenure over all observations is about 140 weeks. $^{11}$

\subsection{Measuring performance}

The main measure of performance used by the call centre is average handling time (AHT). It is defined as the time taken for talking to the customer, plus

\footnotetext{
${ }^{9}$ Barzel (1973) studies how working hours are determined by the interplay of supply and demand when the remuneration of an extra hour of work varies together with the product of that extra hour. In our setting, workers are paid a constant hourly wage rate, and therefore face the linear budget constraint which is usually assumed in the standard model of labour supply. Therefore, our findings about the relation between hours and labour productivity are mainly relevant for the demand side of the labour market.

${ }^{10}$ We observe the results of the annual performance appraisals only for a subsample of agents. In these data, only very few agents receive the worst and the best grade (1: $1.3 \%$; 5: $0.7 \%$, while most agents receive a $2(29.9 \%), 3(54.6 \%)$, or $4(13.6 \%)$, respectively. The criteria for performance appraisals are agents' performance scorecards throughout the year, as well as the behaviour of the agent towards co-workers and team leader.

${ }^{11}$ The firm's administrative data includes a small number of outliers. We therefore kept only observations with positive values for hours and performance, and excluded from the sample half a percentile at the top of the performance and the working hours distribution.
} 
time taken for logging the information in the firm's database. On average, agents take 322 seconds, or 5.35 minutes, to handle a call. Figure 1 shows the density of average handling time and shows that the distribution is rightskewed. Earlier studies using performance data of call agents have used similar measures to estimate the impact of training and learning on-thejob on performance (Liu and Batt, 2007; De Grip and Sauermann, 2012; Breuer et al., 2013; De Grip et al., 2016). Panel (a) of Figure 2 depicts the descriptive relationship between our measure of productivity (1/AHT) and daily working time. Longer working hours seem to be associated with slightly lower productivity, i.e. slightly longer average handling times.

While it is relatively straightforward to measure how long agents take for an average call, it is more difficult to measure the quality of these calls. We use two different measures of quality. The first is the share of repeat calls. The system tracks when customers are calling again within seven days after the last call. Based on this information, the system calculates the share of customers who call back within 7 days, relative to all customers an agent had contact with. The higher the share of repeat calls, the lower service quality. Zero repeat calls indicates that none of the customers an agent had contact with was calling back within seven days. A value of 1 would indicate that every customer would have called back. ${ }^{12}$

A second variable, which is used to assess the quality provided by agents, is front line completion. This variable is based on the inbound and outbound calls. Since the main task of agents is to receive inbound calls, and outbound calls should only be necessary if an agent could not complete a case, a lower front line completion rate is an indicator of lower quality. Completion is defined as the difference between an agent's number of inbound calls and outbound calls, divided by the number of inbound calls. The measure is 1 if an agent does no outbound calls at all. Thus, a value of 1 reflects high problem-solving ability of the agent.

\footnotetext{
${ }^{12}$ One disadvantage of this measure is that customers might have called back for a different reason, which might be unrelated to the original call. In this case, the "repeat" call would be wrongly attributed to an agent.
} 


\subsection{Measuring working time}

Working time is calculated as the number of calls handled by an individual agent, times the agent's average handling time. It thus measures the time during which an agent is directly working on his or her main task, answering customer calls. By definition, this measure does not comprise any non-call related time, such as breaks, slack, or training hours. We choose this measure because it serves as a precise measure of effective working time. If we used a measure which includes slack time and breaks, part of what would be counted as working time would actually be recovery time. This would lead to an underestimation of the fatigue effect. Moreover, slack time or time for breaks is most probably not proportional to the time spent answering calls. Rules about breaks, for instance, prescribe different break schemes for different discrete values of time spent at the workplace. Therefore, the share of time spent in breaks is not constant across values of time spent at the workplace. This could also lead to bias in the estimated fatigue effect if we used a measure of working time which includes breaks. ${ }^{13}$

To analyse how important our choice of the definition of working hours is, we also consider two alternative measures of working time in our estimations in the next section. The first is a measure of hours during which the agent is available to answer calls at his or her desk. The second is a measure of the time spent by the agent at the workplace, and includes training, the unpaid lunch break, etc. They are not, however, precise enough to yield reliable information about slack time and time spent in breaks.

Table 1 also provides summary statistics of these alternative measures of working time. Both measures are very strongly correlated with the measure we chose, in particular the time that agents are available for calls $(\rho=0.95)$. Most agents working in the call centre work part time. On average, agents spend 4 days a week and 6 hours per day at their workplace. Their effective working time, however, only averages 4.6 hours per day, and 17.7 hours per week.

\footnotetext{
${ }^{13}$ It would be very interesting to study the role played by slack time and breaks, and whether they function as recovery time for workers (cf. Pencavel, 2016). However, the data we have does not allow us to do so.
} 
Table 2 shows that there is sufficient within-agent variation in the number of hours worked per day and per week. Agents work days of about 5 effective working hours about half (45.8 percent) of the time. However, during the rest of the time, they work very different numbers of hours per day, ranging from about 0 to about 8 hours. At the week level, the number of observations peaks at around 24 hours a week. About 70 percent of agents in the sample have at least one working week of that length, but there is still quite some variation in the length of the working week across observations and agents.

In addition to the information on working hours, the data also contain information on the total number of scheduled hours for each individual in each week.

\section{Estimation results}

In this section, we present the results of estimating the relation between working hours and productivity. We first address our main measure of productivity, $\ln (1 / A H T)$, and then the two measures of the quality of calls. As mentioned above, we conduct the estimations both at the daily and at the weekly level.

\subsection{Working hours and productivity}

Table 3 presents estimation results of a regression of productivity on working hours at the daily level, including different control variables. Regardless of the specification, productivity appears to decrease slightly as working hours increase. As the number of controls included in the model increases, the estimated relationship between working time and productivity tends to become less negative. In particular, controlling for the timing of shifts (day of the week and hour dummies) leads to a lower estimate of the fatigue effect. This is because shifts at atypical times, such as nights and weekends, tend to be both shorter and more productive. There are two likely explanations for this. First, agents have less calls to handle, creating slack time to rest between calls. Second, the call centre is open only for very specific types of calls 
during the night and during the weekend, which could be shorter by nature. Consequently, fatigue is overestimated when timing is not controlled for. ${ }^{14}$ Our preferred specification is shown in Column (7). The interpretation of the coefficient on $\ln (H), \beta$, is that output increases by $\beta+1$ percent as hours increase by 1 percent (see Subsection 2.1). Therefore, our estimation results suggest that if working hours increase by 1 percent, the number of calls handled will only increase by 0.9 percent. This suggests that, as agents work longer hours, fatigue makes agents work slower. The log-log specification appears to fit the data. The $R^{2}$ statistic is higher for this specification than for a linear or a quadratic one. Panel (b) of Figure 2, which plots the coefficients obtained from a regression of productivity on a set of dummies for 15-minute working time intervals, and therefore does not impose any functional form on the data, also hints at a negative logarithmic relationship between working time and productivity. ${ }^{15}$ In Column (8), we include individual-level characteristics. The estimates show that, although agents perform less well with increasing age, tenure significantly improves productivity (cf. De Grip et al., 2016). The performance of male and female call agents does not, however, differ significantly.

Table 4 presents regressions of productivity on working time at the week level. The magnitude of the negative effect appears less important at the week level, compared to the results at the day level. This could be explained by the fact that people have the time to rest from one day to another. The idea that agents have time to recover from one day to the other is further supported by the fact that we find no relationship between productivity on a

\footnotetext{
${ }^{14}$ If we exclude observations, for which the shifts starts before 09:00 or ends after 21:00, we obtain very similar results, with a coefficient on log working hours of $-0.105^{* * *}$. Likewise, if we exclude observations from Saturdays and/or Sundays, the estimates are almost identical to the ones shown in Column (7) of Table $3\left(-0.113^{* * *}\right)$.

${ }^{15}$ To allow for potential non-linearities in the effect of working hours on performance, we also estimated the regression shown in Column (7) of Table 3, allowing for structural breaks above/below which the effects of working hours could be stronger/weaker. We do not find any significant structural breaks in our estimations. The results are available upon request.
} 
given day and the number of hours worked on previous days. ${ }^{16}$ Column (2) in Table 4 indeed suggests that it is worth spreading hours worked over more days. In that specification, total hours worked in a week are decomposed into number of days worked and average number of hours worked per day in that week. The returns to days per week seem to be slightly higher than the returns to hours per day. The difference between both coefficients is, however, not statistically significant.

Table 5 presents estimation results using the two alternative measures of working time we have: (1) time available for calls and (2) time present at the workplace. As hypothesised above, the estimated fatigue effects are smaller if slack time is included in the measure of working time. They even disappear when breaks are included. When using a measure of working time which includes breaks, one would be inclined to conclude that output is proportional to working time and that there are no fatigue effects. However, the evidence presented in Tables 3 and 4 on the relationship between effective working time and productivity shows that this would be misleading.

\subsection{Working hours and call quality}

Table 6 presents the estimation results of a regression of different quality indicators on working time and a series of controls, at both the day and the week level. Call quality, as measured by repeat calls and front line completion, slightly increases in the number of working hours. Column (1) shows that one additional working hour is related to a decrease in the share of repeat calls by 0.005 , which translates to a decrease by $6 \%$ of a standard deviation. Since high shares of repeat calls are equivalent to low performance, agents with longer hours improve on this quality measure. Column (2) shows that one additional working hour is related to an increase in the front line completion rate by 0.018 , or $25 \%$ of a standard deviation. The effects on call quality measured at the weekly level are of similar size.

\footnotetext{
${ }^{16}$ These results are available from the authors. Pencavel (2016) does find evidence that long working hours negatively affect productivity in subsequent weeks for munition workers. This does not seem to be the case for call centre agents.
} 
Although the effect size is small, the results show that agents are providing better calls if working longer hours. We can only speculate about the reason for this observed increase in quality with working hours. First, this may be due to a learning effect if many of the problems for which customers are specific for a given day and agents learn how to resolve them during the course of that day. Second, this may be the result of what Vernon (1921) calls "practice-efficiency", if call agents are better able to tune in to customers' demands as they spend more time at their desk, get used to answering calls and leave other thoughts behind. For both arguments to be true, however, the mechanisms should enable the agents to provide a better solution to consumers' problems but not enable them to help customers quicker, otherwise we would observe a positive effect of working hours on average handling time. A third possibility is that there is a trade-off between speed and quality and that agents provide better quality because they slow down has they have been working for a while. ${ }^{17}$

Taken together, the results show that, as agents work longer hours, they become slower, meaning that they score worse on the quantity of output, whereas quality slightly increases.

\section{Robustness checks}

In Section 3, we discussed potential sources of endogeneity in our estimations. In this section, we check whether these potential problems indeed play a role in our data.

\subsection{Tenure and attrition}

One potential confounder in the relationship between working time and productivity is tenure. The results so far controlled for individual fixed effects that should account for differences in tenure between individuals at the start

\footnotetext{
${ }^{17}$ An alternative explanation for the positive relation between working hours and call quality would be that in times of high customer demand, customers would be less likely to call back. Because results for both repeat calls and front line completion confirm our interpretation, we do not think that this is a likely explanation.
} 
of the observation period. If, however, more productive agents have lower turnover than less productive agents, high-productivity agents could be overrepresented in the sample. In this case, we may overestimate the returns to hours, or underestimate the effects of fatigue.

To account for potential differences in how fast individuals learn on the job, we estimate a model in which we control for an individual-specific time trend (i.e. an interaction of the individual fixed effect with the time trend). Table 7 presents the estimation results, both at the day and at the week level. The individual-specific time trends typically have positive coefficients, confirming the idea that individuals learn on the job. Controlling for a (daily or weekly) time trend at the individual level does not affect the estimated coefficient on hours worked much, compared to the results in Tables 3 and 4. This suggests that differences in learning speed between individuals are not an important confounder. ${ }^{18}$

To check for the role of selective tenure, we estimate the model for different sub-samples of our data: (1) including only shifts which take place during the first year of tenure of an individual, (2) including only shifts which take place after the first year of tenure of an individual, and (3) including only the first half year of observation, and only shifts of individuals who are present during all of this first half year, to proxy a balanced panel in terms of tenure. ${ }^{19}$ The results are presented in Table 8 . The coefficient on hours worked is much larger for individuals with short tenure than for individuals with long tenure. This suggests that fatigue plays a much larger role for agents early in their career than for experienced agents. ${ }^{20}$ This finding is consistent with evidence that the need for recovery increases as workers' skills are below what is re-

\footnotetext{
${ }^{18}$ Instead of assuming a linear individual time trend, we also estimated the same model with fixed effects interacting the agent with months and year dummies to allow for nonlinear individual-specific time effects. The results, which are available from the authors, result in a very similar point estimate as the ones presented in Table 7.

${ }^{19}$ The panel is not exactly balanced, because the individuals of this sub-sample are not observed for exactly the same number of days. But this sub-sample is useful to check whether the potential overrepresentation of individuals with long tenure in the data leads to bias in the estimations.

${ }^{20}$ The results for a sub-sample of individuals who are in their first half year of tenure are very similar to those for individuals in their first year.
} 
quired for their job (Gommans et al., 2016). If workers learn on the job, they should be less subject to fatigue as they become more experienced. But the finding of smaller fatigue effects for agents with longer tenure is also consistent with the idea that tenure is selective, in the sense that agents who are less subject to fatigue are more likely to remain in the call centre. In any case, the effect of hours estimated in Table 3 actually covers heterogeneous effects which depend on the tenure of an agent. Further, the coefficient on hours obtained in Column (3) of Table 8 is very similar to the one obtained in Table 3. As our results are similar whether we use a balanced panel or not, attrition does not seem to be an important source of bias.

In estimations at the week level, we also observe a much stronger fatigue effect for agents with less than a year tenure than for agents with more than a year of experience. The fatigue effect even seems to be entirely driven by individuals in their first year of tenure, and to disappear entirely for experienced agents at the week level. A possible explanation could be that experienced agents are better able to recover from one day to another. Estimation of a balanced panel yields results similar to those obtained in Table 4 , suggesting that attrition does not bias the results. ${ }^{21}$

\subsection{Scheduling as a source of exogeneity in hours worked}

In Section 3, we argued that scheduling by the planning department of the call centre ensures that the number of hours worked by an agent on a given day or in a given week is exogenous. We also mentioned potential objections to this argument: individuals can express schedule preferences for a specific day or week, and they may be asked to stay shorter or longer in case of unforeseen changes in the number of incoming calls. We address these objections here.

In Table 9, we estimate our preferred models at the day and week level, including additional controls for the number of hours scheduled (Columns (1) and (3)) or the deviation from the number of hours scheduled, defined as

\footnotetext{
${ }^{21}$ Results available from the authors. For individuals in their first year of tenure and for the balanced sample, the results described here are only found after the week fixed effects and the time trend are dropped out of the model. Estimation of the model with the full set of controls seems to be hampered as the number of observations is reduced.
} 
the difference between actual hours worked and scheduled hours for a week (Columns (2) and (4)). ${ }^{22}$

The positive coefficient on hours scheduled in Columns (1) and (3) of Table 9 suggests that individuals are indeed more (less) productive in weeks for which their expressed preferences ensured that they were scheduled for longer (shorter) hours. However, controlling for the length of schedules does not lead to important changes in the estimated magnitudes of the coefficients on working time. They are only slightly more negative, hinting at a slight underestimation of the fatigue effect due to selective scheduling.

The results in Columns (2) and (4) show that hours worked on top of scheduled hours are negatively related to productivity. It suggests that fatigue becomes even stronger if the effort to be made by agents is unexpected. This is intuitive, and is evidence against self-selection of agents in the sense that they would volunteer to work more hours on days on which they are more productive. The coefficient on working time becomes slightly less negative in this specification, which is logical because the total fatigue effect (as estimated in Tables 3 and 4) is now decomposed into "simple" fatigue due to working more hours and additional fatigue during unexpected extra hours. All in all, the evidence presented in Table 9 suggests that self-selection by agents is not an important source of bias in our estimations. Rather, it seems plausible that scheduling exogenously determines the hours actually worked by agents.

\section{Conclusions}

In this paper, we have estimated the impact of working time on productivity, both at the daily and at the weekly level. We have used panel data on individual workers of a call centre in the Netherlands, which contain information about the number of hours worked, the number of calls answered, the average

\footnotetext{
${ }^{22}$ The number of observations drops because information about scheduled hours is not available for every agent. If we limit the estimation sample to agents with strictly positive scheduled hours, the results remain very similar, only the coefficient on scheduled hours becomes smaller. If we take up the log scheduled hours and log deviation in the models instead of scheduled hours and deviation, the results remain virtually unchanged.
} 
handling time of calls and indicators of call quality for every day worked by an agent from mid-2008 until the first week of 2010. The panel character of the data enables us to control for time-invariant unobserved heterogeneity. Scheduling by the firm generates variation in the daily and weekly hours of individual workers which is hardly related to individual time-varying characteristics, since expected consumer demand is leading in making schedules. This yields estimates of the effect of working time on productivity that are not biased by individual shocks.

Our results show that an increase in effective working time by 1 percent leads to an increase in output, i.e. the number of calls answered, by about 0.9 percent. This corresponds to moderately decreasing returns to hours, probably due to fatigue among agents. Given that agents in our sample work on average 4.6 effective hours per day, this shows that the call centre environment is demanding and that fatigue sets in early. The fatigue effects would be larger if the call agents worked full-time. This study complements the small number of studies which examine the effect of working time on productivity using an arguably exogenous source of variation in working time (Crocker and Horst, 1981; Brachet et al., 2012; Pencavel, 2015; Dolton et al., 2016), by providing evidence for medium-skilled jobs in the service sector. As we are able to isolate effective working time and concentrate on this measure, our estimates form an upper bound for the fatigue effect. Our finding of decreasing returns to hours seems to hold best for individuals with shorter tenure, while we find much less evidence of fatigue effects among more experienced agents. Various indicators of call quality show that call quality does not suffer as the number of hours worked increase. On the contrary, call quality seems to slightly improve.

Our findings are most relevant for part-time medium-skilled jobs in the service sector. They suggest that increasing the effective working time in these occupations would cause individual workers, in particular the relatively inexperienced ones, to produce smaller quantities of output per hour, due to fatigue. Such an increase in working time could, however, be beneficial for the quality provided. These findings are informative for firm management and for working time regulation policies. The total economic effects of such 
policies, however, are dependent not only on the effect of working hours on labour productivity at the individual level, but also on many more factors such as work organisation and availability of qualified workers.

\section{References}

Anxo, D. And A. Bigsten (1989): "Working Hours and Productivity in Swedish Manufacturing," Scandinavian Journal of Economics, 91, 613619.

Bakker, A., E. Demerouti, And W. Schaufeli (2003): "Dual processes at work in a call centre: An application of the job demands-resources model," European Journal of work and organizational psychology, 12, 393417.

BArzel, Y. (1973): "The Determination of Daily Hours and Wages," The Quarterly Journal of Economics, 87, 220-238.

Bick, A., B. Brüggemann, And N. Fuchs-Schündeln (2016): "Hours Worked in Europe and the US: New Data, New Answers," IZA Discussion Papers 10179, Institute for the Study of Labor (IZA).

Brachet, T., G. David, And A. M. Drechsler (2012): "The Effect of Shift Structure on Performance," American Economic Journal: Applied Economics, 4, 219-246.

Breuer, K., P. Nieken, And D. Sliwka (2013): "Social ties and subjective performance evaluations: an empirical investigation," Review of managerial Science, 7, 141-157.

Craine, R. (1973): "On the Service Flow from Labour," Review of Economic Studies, 40, 39-46. 
Crépon, B., M. Leclair, And S. Roux (2004): "RTT, productivité et emploi: nouvelles estimations sur données d'entreprises," Economie et statistique, 376, 55-89.

Crocker, T. D. And R. L. Horst (1981): "Hours of Work, Labor Productivity, and Environmental Conditions: A Case Study," Review of Economics and Statistics, 63, 361-368.

De Grip, A. And J. Sauermann (2012): "The Effects of Training on Own and Co-worker Productivity: Evidence from a Field Experiment," Economic Journal, 122, 376-399.

De Grip, A., J. Sauermann, and I. Sieben (2016): "TenurePerformance Profiles and the Role of Peers: Evidence from Personnel Data," Journal of Economic Behavior \& Organization, 126, 679-695.

DeBeaumont, R. And L. D. Singell (1999): "The Return to Hours and Workers in U. S. Manufacturing: Evidence on Aggregation Bias," Southern Economic Journal, 66, 336-352.

Devicienti, F., E. Grinza, and D. Vannoni (2015): "The Impact of Part-Time Work on Firm Total Factor Productivity: Evidence from Italy," IZA Discussion Papers 9463, Institute for the Study of Labor (IZA).

Dolton, P., C. Howorth, and M. Abouaziza (2016): "The Optimal Length of the Working Day: Evidence from Hawthorne Experiments," ESPE conference paper.

Feldstein, M. S. (1967): "Specification of the labour input in the aggregate production function," Review of Economic Studies, 34, 375-386.

Garnero, A., S. Kampelmann, and F. Rycx (2014): "Part-Time Work, Wages, and Productivity Evidence from Belgian Matched Panel Data," Industrial \& Labor Relations Review, 67, 926-954.

Gianella, C. And P. Lagarde (2011): "Productivity of hours in the aggregate production function: An evaluation on a panel of French firms from the manufacturing sector," Tech. rep., Insee. 
Goldmark, J. (1912): Fatigue and Efficiency: A Study in Industry, New York: Russel Sage.

Gommans, F., N. Jansen, D. Stynen, I. Kant, and A. De Grip (2016): "The impact of underskilling on need for recovery, losing employment and retirement intentions among older office workers: A prospective cohort study," International Labour Review, forthcoming.

Hart, A. And S. Krall (2007): “220: Productivity: Do 8-9 Hour Shifts Make a Difference?" Annals of Emergency Medicine, 50, S69-S70.

Hart, R. A. And P. G. McGregor (1988): "The returns to labour services in West German manufacturing industry," European Economic Review, 32, 947-963.

Ilmakunnas, P. (1994): "Returns to workers and hours in Finnish manufacturing," Empirical Economics, 19, 533-553.

Kodz, J., S. Davis, D. Lain, M. Strebler, J. Rick, P. Bates, J. Cummings, N. Meager, D. Anxo, S. Gineste, et Al. (2003): "Working long hours: A review of the evidence. Volume 1-Main report," Employment Relations Research Series, 16.

Kossoris, M. D. (1947): "Hours of work and output," Monthly Labor Review, 65,5 .

Kramarz, F., P. Cahuc, B. Crépon, T. Schank, O. N. Skans, G. VAn Lomwel, AND A. Zylberberg (2008): "Labour market effects of work-sharing arrangements in Europe," in Working hours and job sharing in the EU and USA: Are Europeans lazy? Or Americans crazy?, ed. by T. Boeri, M. Burda, and F. Kramarz, Oxford University Press, $171-196$.

Künn-Nelen, A., A. De Grip, And D. Fouarge (2013): "Is part-time employment beneficial for firm productivity?" Industrial \& Labor Relations Review, 66, 1172-1191. 
LEE, J. AND Y.-K. LEE (2016): "Can working hour reduction save workers?" Labour Economics, 40, 25-36.

LeSLIE, D. (1984): "The Productivity of Hours in U.S. Manufacturing Industries," Review of Economics and Statistics, 66, 486-490.

Leslie, D. And J. Wise (1980): "The Productivity of Hours in U.K. Manufacturing and Production Industries," Economic Journal, 90, 74-84.

LiU, X. AND R. BATt (2007): "The economic pay-offs to informal training: evidence from routine service work," Industrial \& Labor Relations Review, $61,75-89$.

Lu, S. F. And L. X. Lu (2016): "Do Mandatory Overtime Laws Improve Quality? Staffing Decisions and Operational Flexibility of Nursing Homes," Management Science, forthcoming.

MCClay, J. (2008): "357: Comparison of Ten-Hour and Twelve-Hour Shifts Demonstrates No Difference in Resident Productivity," Annals of Emergency Medicine, 52, S151.

Nyland, C. (1989): Reduced worktime and the management of production, Cambridge: Cambridge University Press.

OECD (2016): OECD Employment Outlook 2016, OECD Publishing.

Pencavel, J. (2015): "The Productivity of Working Hours," Economic Journal, 125, 2052-2076.

- (2016): "Recovery from Work and the Productivity of Working Hours," Economica, 83, 545-563.

Rogers, A. E., W.-T. Hwang, L. D. Scott, L. H. Aiken, and D. F. Dinges (2004): "The working hours of hospital staff nurses and patient safety," Health Affairs, 23, 202-212.

Schank, T. (2005): "Are overtime plants more efficient than standard-time plants? A stochastic production frontier analysis using the IAB Establishment Panel," Empirical Economics, 30, 693-710. 
Shepard, E. And T. Clifton (2000): "Are longer hours reducing productivity in manufacturing?" International Journal of Manpower, 21, 540553.

Specchia, G. and V. Vandenberghe (2013): "Is Part-time Employment a Boon or Bane for Firm Productivity?" Tech. rep., IRES Working Paper.

Tatom, J. A. (1980): "The "Problem" of procyclical real wages and productivity," Journal of Political Economy, 88, 385-394.

VAN DER HUlST, M. (2003): "Long workhours and health," Scandinavian Journal of Work, Environment \&3 Health, 29, 171-188.

van DiJk, F. J. H. and G. M. H. Swaen (2003): "Fatigue at work," Occupational and Environmental Medicine, 60, i1-i2.

Vegso, S., L. Cantley, M. Slade, O. Taiwo, K. Sircar, P. Rabinowitz, M. Fiellin, M. Russi, And M. Cullen (2007): "Extended work hours and risk of acute occupational injury: A case-crossover study of workers in manufacturing," American Journal of Industrial Medicine, $50,597-603$.

Vernon, H. M. (1921): Industrial fatigue and efficiency, London: Routledge \& Sons. 


\section{Figures}

Figure 1: Density of daily productivity

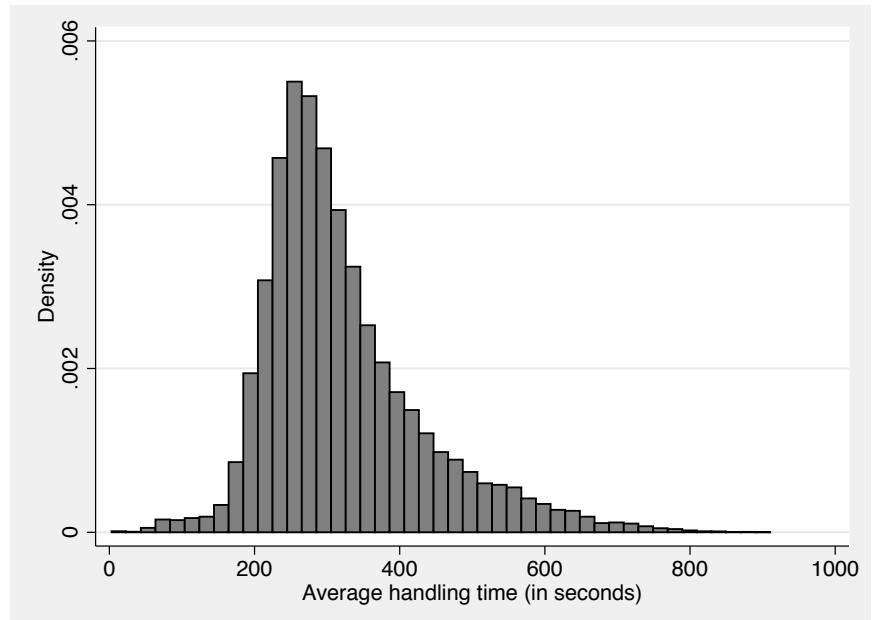

Note: The figure shows how the density plot of daily productivity, as measured by the average handling time (in seconds).

Figure 2: Productivity by working hours

(a) Descriptive results

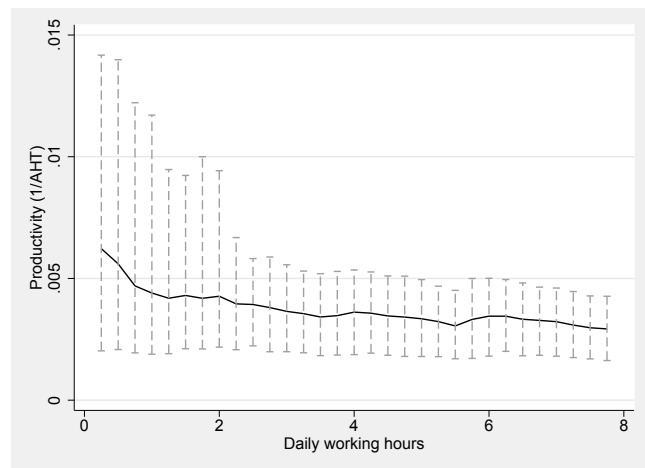

(b) Estimation results

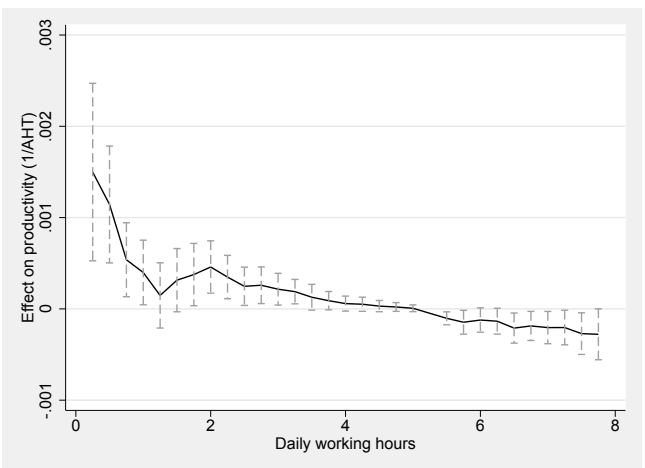

Note: Panel (a) shows average productivity over working time for 15-minute intervals. The capped spikes present the corresponding 5th and 95th percentile of the productivity distribution. Panel (b) shows the coefficients on dummies for 15-minute working time intervals in a regression as in model (7) from Table 3. The capped spikes present the corresponding 95-percent confidence intervals. The reference category is 21 quarters of an hour, i.e. 5 hours and 15 minutes. 


\section{Tables}

Table 1: Descriptive statistics

\begin{tabular}{lccccc}
\hline \hline \multicolumn{1}{c}{ Variable } & Mean & Std. Dev. & Min. & Max. & N \\
\hline Day level & & & & & \\
Average handling time (AHT) & 321.613 & 111.012 & 3 & 910.364 & 33,123 \\
Productivity (1/AHT) & 0.004 & 0.003 & 0.001 & 0.333 & 33,123 \\
Calls Answered & 55.795 & 22.992 & 1 & 129 & 33,123 \\
Daily working hours & 4.621 & 1.516 & 0.001 & 7.747 & 33,123 \\
Starting time & 11.445 & 3.079 & 1 & 24 & 33,120 \\
Share of repeat calls & 0.164 & 0.084 & 0 & 1 & 33,123 \\
Front line completion rate & 0.956 & 0.072 & 0 & 1 & 32,831 \\
Working hours & 4.621 & 1.516 & 0.001 & 7.747 & 33,123 \\
Hours available for calls & 4.812 & 1.414 & 0.001 & 7.903 & 33,123 \\
Hours present at the workplace & 6.05 & 1.476 & 0.01 & 9.52 & 33,123 \\
\hline Week level & & & & & \\
Average handling time (AHT) & 319.314 & 100.133 & 5 & 910.364 & 8,641 \\
Productivity (1/AHT) & 0.003 & 0.002 & 0.001 & 0.2 & 8,641 \\
Calls answered & 213.876 & 114.138 & 1 & 645 & 8,641 \\
Weekly working hours & 17.712 & 8.458 & 0.001 & 43.046 & 8,641 \\
Days per week & 4.020 & 1.282 & 1 & 7 & 8,641 \\
Tenure in weeks & 149.58 & 191.623 & 1 & 691 & 8,587 \\
Share of repeat calls over week & 0.167 & 0.066 & 0 & 1 & 8,641 \\
Front line completion rate over week & 0.950 & 0.083 & 0 & 1 & 8,641 \\
Working hours & 17.712 & 8.458 & 0.001 & 43.046 & 8,641 \\
Hours available for calls & 18.447 & 8.334 & 0.001 & 42.929 & 8,641 \\
Hours present at the workplace & 23.191 & 9.775 & 0.02 & 50.56 & 8,641 \\
Hours scheduled for the week & 19.805 & 9.573 & 0 & 51 & 6,513 \\
\hline Agent level & & & & & \\
N of agents & & & & & 332 \\
Male & 0.351 & 0.478 & 0 & 1 & 305 \\
Age & 29.542 & 10.578 & 17 & 65 & 284 \\
\hline \hline
\end{tabular}


Table 2: Variation in daily and weekly working hours

\begin{tabular}{|c|c|c|c|}
\hline $\begin{array}{lr}\text { Day } & \text { level: } \\
\text { Working } & \text { hours } \\
h(\text { rounded at } 1)\end{array}$ & $\begin{array}{l}\text { Observations with } \\
h \text { hours }\end{array}$ & $\begin{array}{l}\text { Individuals with } h \\
\text { hours at least once }\end{array}$ & $\begin{array}{l}\text { Conditional on working } h \text { hours } \\
\text { at least once, share of days in } \\
\text { which individual works } h \text { hours }\end{array}$ \\
\hline 0 & 473 & 135 & 2.74 \\
\hline 1 & 1211 & 192 & 6.13 \\
\hline 2 & 1663 & 215 & 6.49 \\
\hline 3 & 3228 & 276 & 11.1 \\
\hline 4 & 5325 & 315 & 17.4 \\
\hline 5 & 14372 & 317 & 45.84 \\
\hline 6 & 3461 & 275 & 12.56 \\
\hline 7 & 3211 & 202 & 17.24 \\
\hline 8 & 179 & 70 & 3.51 \\
\hline Total & 33,123 & & \\
\hline $\begin{array}{l}\text { Week level: } \\
\text { Working hours } h \\
\text { (rounded at } 4 \text { ) }\end{array}$ & $\begin{array}{l}\text { Observations with } \\
h \text { hours }\end{array}$ & $\begin{array}{l}\text { Individuals with } h \\
\text { hours at least once }\end{array}$ & $\begin{array}{l}\text { Conditional on working } h \text { hours } \\
\text { at least once, share of weeks in } \\
\text { which individual works } h \text { hours }\end{array}$ \\
\hline 0 & 187 & 92 & 7.25 \\
\hline 4 & 725 & 227 & 13.6 \\
\hline 8 & 997 & 224 & 17.2 \\
\hline 12 & 1124 & 245 & 15.46 \\
\hline 16 & 1262 & 247 & 17.68 \\
\hline 20 & 1229 & 249 & 20.37 \\
\hline 24 & 1621 & 232 & 27.02 \\
\hline 28 & 968 & 189 & 19.95 \\
\hline 32 & 350 & 114 & 13.1 \\
\hline 36 & 171 & 66 & 11.78 \\
\hline 40 & 6 & 6 & 8.11 \\
\hline 44 & 1 & 1 & 9.09 \\
\hline Total & 8,641 & & \\
\hline
\end{tabular}


Table 3: Relationship between productivity and working time at the day level

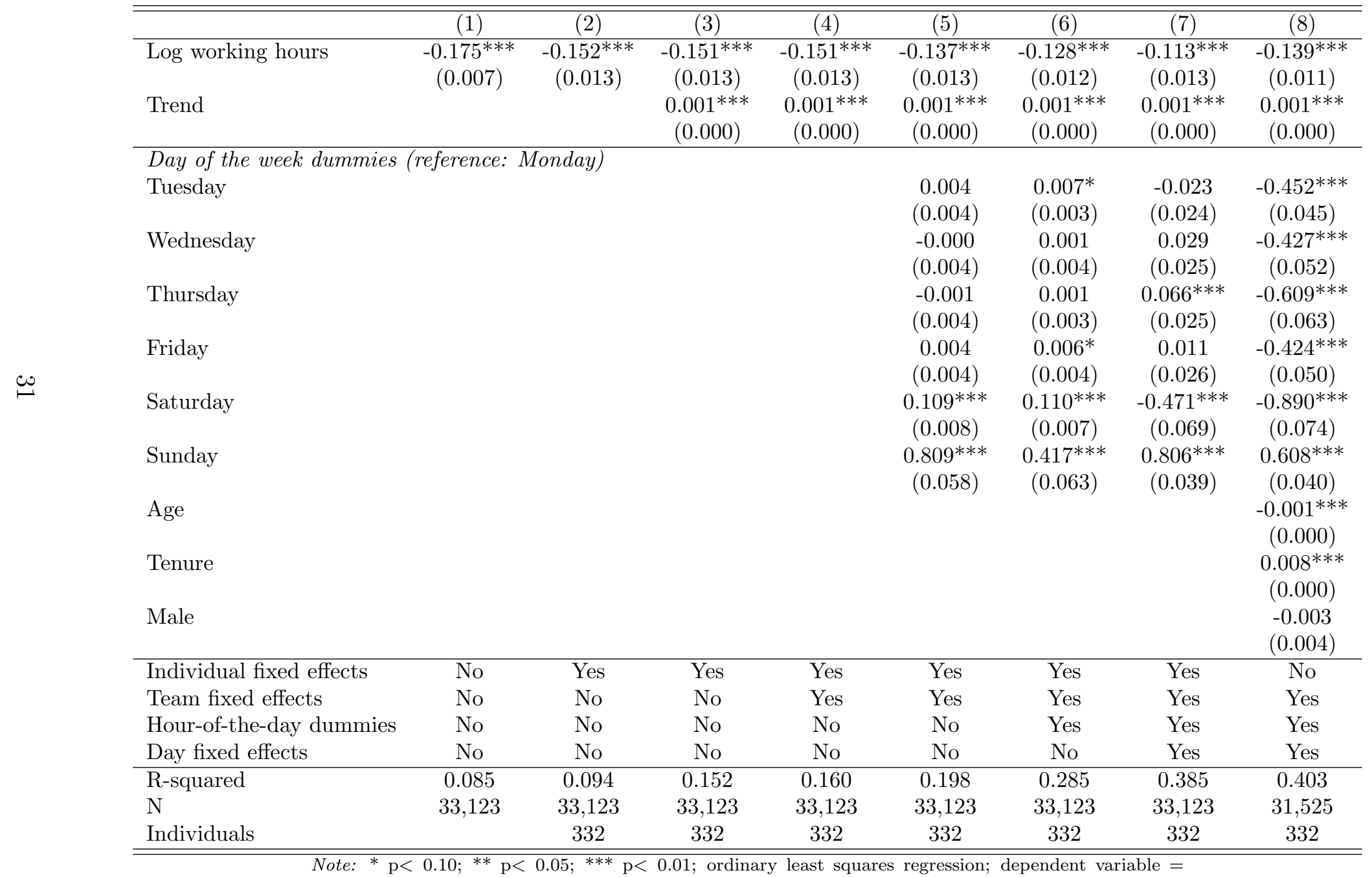

$\mathrm{p}<0.10 ;$
$\ln (1 / A H T) ;$ robust standard errors in parentheses. 
Table 4: Relationship between productivity and working time at the week level

\begin{tabular}{lcc}
\hline \hline & $(1)$ & $(2)$ \\
\hline Log weekly working hours & $-0.078^{* *}$ & \\
& $(0.031)$ & \\
Log days per week & & $-0.066^{* *}$ \\
& & $(0.032)$ \\
Log average hours per day & & $-0.079^{* *}$ \\
& & $(0.031)$ \\
Trend (weekly) & $0.004^{* * *}$ & $0.004^{* * *}$ \\
& $(0.001)$ & $(0.001)$ \\
\hline R-squared & 0.345 & 0.345 \\
N & 8,641 & 8,641 \\
Individuals & 332 & 332 \\
\hline \hline
\end{tabular}

Note: $* \mathrm{p}<0.10 ; * * \overline{\overline{\mathrm{p}<0.05 ;}{ }^{* * *} \mathrm{p}<0.01 ; \text { ordinary least squares regression; }}$ dependent variable $=$ $\ln (1 / A H T)$; robust standard errors in parentheses. All regressions include agent, week, and team fixed effects. The regressions also include hour-of-the-week fixed effects, which are defined as 168 dummies for each hour of the week during which an individual works.

Table 5: Alternative working time definitions and the relationship between productivity and working time

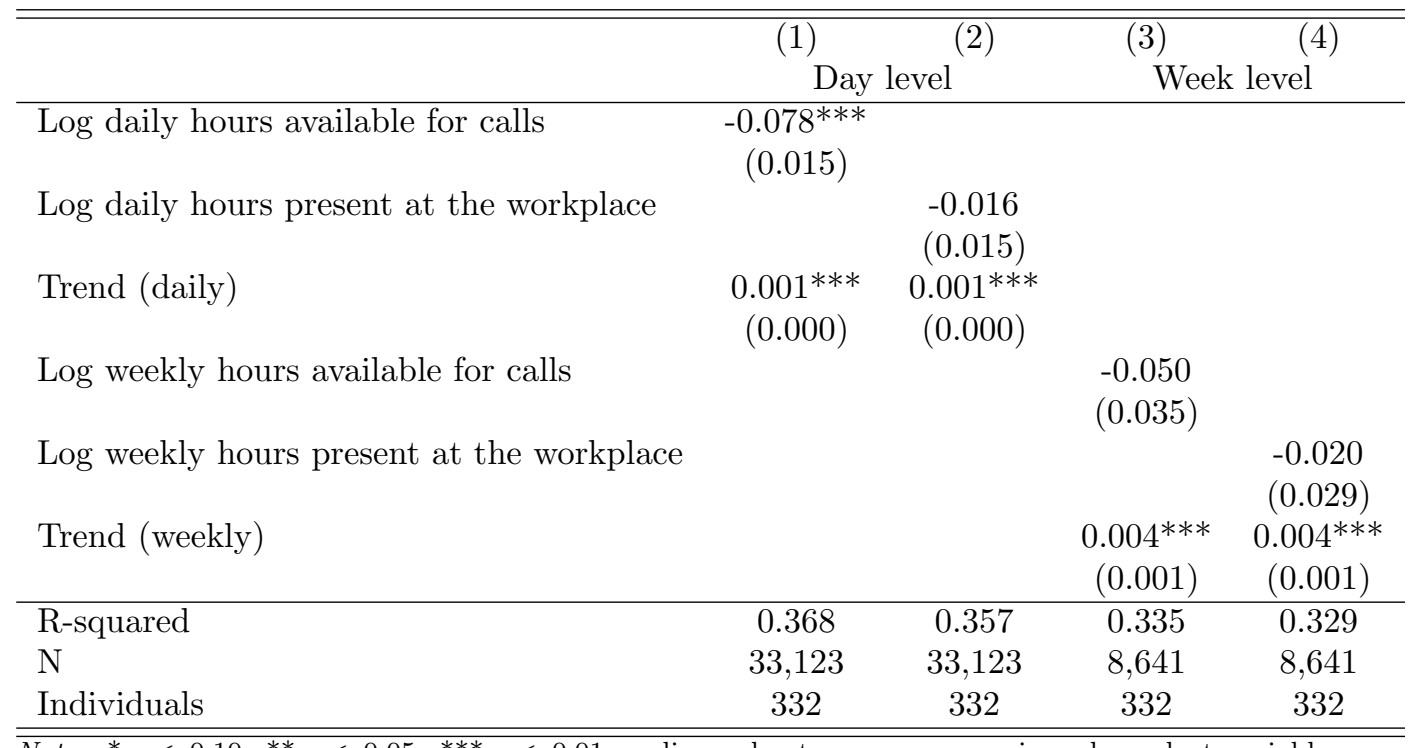

Note: ${ }^{*} \mathrm{p}<0.10 ;{ }^{* *} \mathrm{p}<0.05 ;{ }^{* * *} \mathrm{p}<0.01 ;$ ordinary least squares regression; dependent variable $=$ $\ln (1 / A H T)$; robust standard errors in parentheses. All regressions include agent and team fixed effects. Regressions at the day level include day fixed effects, hour-of-the-day fixed effects and day-of-the-week fixed effects. Regressions at the week level include week fixed effects and hour-of-the-week fixed effects. Day-of-the-week (hour-of-the-week) fixed effects are defined as dummies for each hour of the day (week) an individual works. 
Table 6: Call quality and working time

\begin{tabular}{|c|c|c|c|c|}
\hline \multirow[b]{3}{*}{$\begin{array}{l}\text { Dependent } \\
\text { Variable }\end{array}$} & (1) & $\overline{(2)}$ & $\overline{(3)}$ & $\overline{(4)}$ \\
\hline & \multicolumn{2}{|c|}{ Day level } & \multicolumn{2}{|c|}{ Week level } \\
\hline & $\begin{array}{l}\text { Repeat } \\
\text { calls }\end{array}$ & $\begin{array}{l}\text { Completion } \\
\text { rate }\end{array}$ & $\begin{array}{l}\text { Repeat } \\
\text { calls }\end{array}$ & $\begin{array}{c}\text { Completion } \\
\text { rate }\end{array}$ \\
\hline Daily working hours & $\begin{array}{c}-0.005^{* * *} \\
(0.001)\end{array}$ & $\begin{array}{c}0.018^{* * *} \\
(0.002)\end{array}$ & & \\
\hline Trend (daily) & $\begin{array}{c}0.000^{* * *} \\
(0.000)\end{array}$ & $\begin{array}{c}0.000 \\
(0.000)\end{array}$ & & \\
\hline Weekly working hours & & & $\begin{array}{c}-0.001^{* * *} \\
(0.000)\end{array}$ & $\begin{array}{c}0.012^{* * *} \\
(0.001)\end{array}$ \\
\hline Trend (weekly) & & & $\begin{array}{c}0.002^{* * *} \\
(0.000)\end{array}$ & $\begin{array}{l}-0.000 \\
(0.000)\end{array}$ \\
\hline R-squared & 0.200 & 0.079 & 0.237 & 0.223 \\
\hline $\mathrm{N}$ & 33,123 & 32,831 & 8,641 & 8,641 \\
\hline Individuals & 332 & 332 & 332 & 332 \\
\hline
\end{tabular}

Note: ${ }^{*} \mathrm{p}<0.10 ;{ }^{* *} \mathrm{p}<0.05 ;{ }^{* * *} \mathrm{p}<0.01 ;$ ordinary least squares regression; robust standard errors in parentheses. All regressions include agent and team fixed effects. Regressions at the day level include day fixed effects, hour-of-the-day fixed effects and day-of-the-week fixed effects. Regressions at the week level include week fixed effects and hour-of-the-week fixed effects. Day-of-the-week (hour-of-the-week) fixed effects are defined as dummies for each hour of the day (week) an individual works. Repeat calls are defined as the share of customers to whom an agent spoke who call back within seven days and is defined on a scale from 0 (best) to 1 (worst). Front line completion is defined as difference between an agent's number of inbound calls and outbound calls, divided by the number of inbound calls. It is defined on a scale from 0 (worst) to 1 (best). 
Table 7: Individual-specific time trends and the relationship between productivity and working time

\begin{tabular}{lcc}
\hline \hline & $(1)$ & $(2)$ \\
& Day level & Week level \\
\hline Log daily working hours & $-0.104^{* * *}$ & \\
& $(0.013)$ & \\
Trend (daily) & $-0.000^{* * *}$ & \\
& $(0.000)$ & \\
Log weekly working hours & & $-0.071^{* *}$ \\
& & $(0.034)$ \\
Trend (weekly) & & $-0.001^{*}$ \\
& & $(0.001)$ \\
\hline Agent-specific day trend & Yes & No \\
Agent-specific week trend & No & Yes \\
\hline R-squared & 0.479 & 0.496 \\
N & 33,123 & 8,641 \\
Individuals & 332 & 332 \\
\hline
\end{tabular}

Note: ${ }^{*} \mathrm{p}<0.10 ; * \overline{\mathrm{p}}<0.05 ;{ }^{* * *} \mathrm{p}<0.01 ;$ ordinary least squares regression; dependent variable $=$ $\ln (1 / A H T)$; robust standard errors in parentheses. All regressions team fixed effects. Regressions at the day level include day fixed effects, hour-of-the-day fixed effects and day-of-the-week fixed effects. Regressions at the week level include week fixed effects and hour-of-the-week fixed effects. Day-of-theweek (hour-of-the-week) fixed effects are defined as dummies for each hour of the day (week) an individual works.

Table 8: Tenure, attrition, and the relationship between productivity and working time at the day level

\begin{tabular}{lccc}
\hline \hline & $(1)$ & $(2)$ & $(3)$ \\
\hline Log daily working hours & $-0.141^{* * *}$ & $-0.078^{* * *}$ & $-0.100^{* * *}$ \\
& $(0.022)$ & $(0.014)$ & $(0.023)$ \\
Trend (daily) & $0.002^{* * *}$ & $0.000^{* * *}$ & -0.000 \\
& $(0.000)$ & $(0.000)$ & $(0.000)$ \\
\hline R-squared & 0.421 & 0.430 & 0.499 \\
$\mathrm{~N}$ & 15,664 & 17,326 & 9,366 \\
Individuals & 249 & 131 & 104 \\
\hline
\end{tabular}

Note: ${ }^{*} \mathrm{p}<0 . \overline{\overline{10 ; * *} \mathrm{p}<0.05 ;{ }^{* * *} \mathrm{p}<0.01 ; \text { ordinary least squares regression; sample }}$ is restricted to individuals with a year tenure or less (Column (1)), with more than a year tenure (Column (2)), and only the first half year of observation and only shifts of individuals who are present during all of this first half year (Column (3)); robust standard errors in parentheses. All regressions include agent, day fixed effects and team fixed effects. Regressions also include hour-of-the-day fixed effects and day-of-the-week fixed effects, which are defined as dummies for each hour of the day and day of the week an individual works. 
Table 9: Relationship between productivity and working time, controlling for weekly schedule

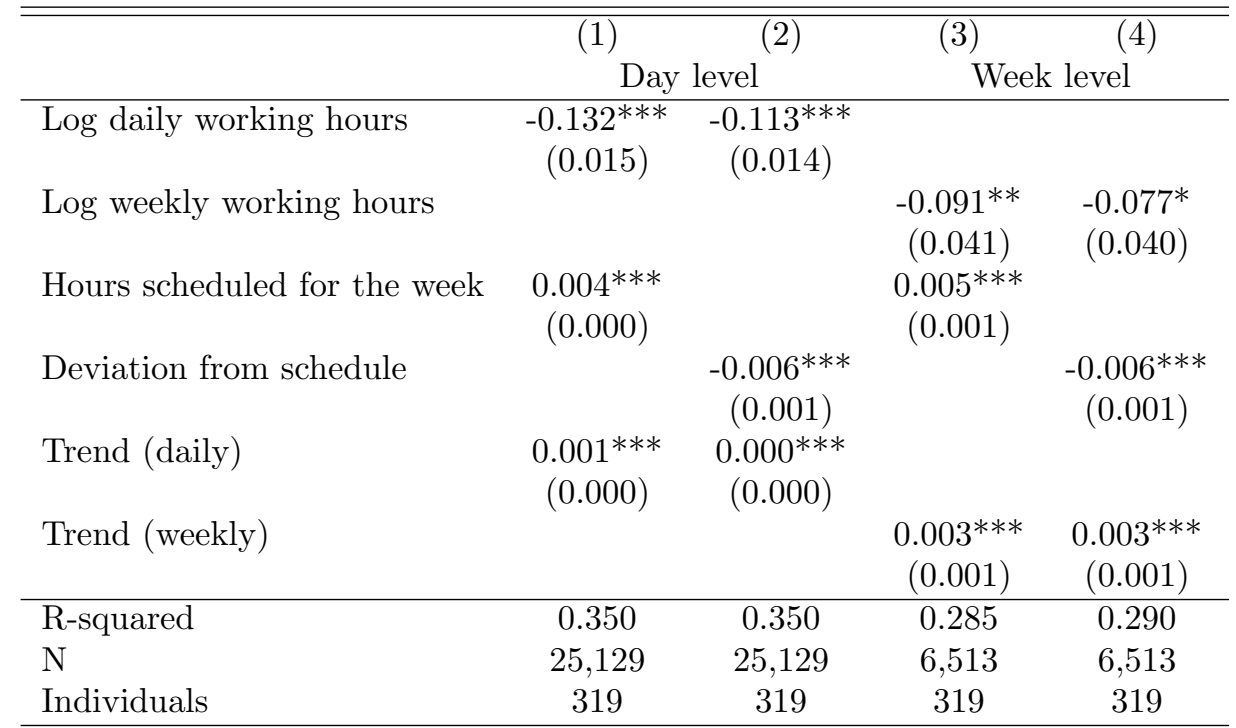

Note: $\overline{{ }^{*} \mathrm{p}<0.10 ;{ }^{* *} \mathrm{p}<0.05 ;{ }^{* * *} \mathrm{p}<0.01 ; \text { ordinary least squares regression; dependent variable }}=$ $\ln (1 / A H T)$; robust standard errors in parentheses. All regressions include agent and team fixed effects. Regressions at the day level include day fixed effects, hour-of-the-day fixed effects and day-of-the-week fixed effects. Regressions at the week level include week fixed effects and hour-of-the-week fixed effects. Day-of-the-week (hour-of-the-week) fixed effects are defined as dummies for each hour of the day (week) an individual works. 